\title{
ON ANTHROPOMETRIC DATA OF THE MALE STUDENT CANDIDATES OF THE INSTITUTE OF SPORT SCIENCES AND PHYSIOTHERAPY AT THE UNIVERSITY OF TARTU IN 2017
}

\author{
Mart Lintsi ${ }^{1}$, Rein Aule ${ }^{3}$, Heiti Annus ${ }^{4}$, Martin Mooses 3 , \\ Mehis Viru ${ }^{3}$, Harry Lemberg ${ }^{3}$, Ando Pehme ${ }^{3}$, \\ Ants Nurmekivi ${ }^{3}$, Helje KaArma ${ }^{1}$, Marina AunapuU ${ }^{2}$, \\ ANDRES AREND ${ }^{2}$ \\ ${ }^{1}$ Centre for Physical Anthropology, ${ }^{2}$ Department of Anatomy at the Institute of \\ Biomedicine and Translational Medicine and ${ }^{3}$ Institute of Sport Sciences and \\ Physiotherapy, Faculty of Medicine, University of Tartu, Tartu, Estonia \\ ${ }^{4}$ Kalev Sports Society, Tartu, Estonia
}

\begin{abstract}
The purpose of this study was to investigate some anthropometric variables of student candidates of the Institute of Sport Sciences and Physiotherapy, Faculty of Medicine, University of Tartu in 2017. All anthropometric measurements were made according to the recommendations of R. Martin [7].

Comparison of the height and weight data of the studied subjects with the height and weight norms of Estonia provided by Kaarma et al. [9] revealed that the entrants were taller in height but with the same average weight.

In our study, the somatotypes recommended by Kaarma et al. [9] were used for the first time on entrants to the university. Our study found that male student candidates' body somatotypes were divided into SD classes as follows: small $8.6 \%$, medium $22.9 \%$, large $18.6 \%$; subtypes of pycnomorphic somatotypes: $7.1 \%$ in class I, $1.4 \%$ in class II, and $8.6 \%$ in class III; leptomorphic somatotypes were divided: $11.4 \%$ in class I, none in class II and $31.4 \%$ in class III.

Based on the recommendations of several authors, we calculated the ideal body weight for all the entrants enrolled in the study.
\end{abstract}


Comparison of the average body weight of entrants with the average weight calculated using the ideal weight method revealed an interesting situation. Namely, the mean values calculated using the Devine (1974) formula did not differ statistically significantly from the mean of the measured weights $(t=0.101, p>0.05)$. Neither did Devine's (1974) ideal weight and BMI, Rohrer's index and ponderal index calculated from it, and the body surface calculated according to the formulas of Dubois and Dubois and Mosteller differ from the actual figures.

Keywords: anthropometry; height; weight; ideal weight; indices

\section{INTRODUCTION}

The founder of contemporary physical anthropology in Estonia, Juhan Aul, considered it important to assess the physical development of a great number of schoolchildren, to pay greater attention to anthropometric studies of women and men and regularly publish papers on anthropology $[1,2,3,4,5]$.

In 1932-1936, Aul investigated the physical anthropology of 15110 servicemen of the Estonian army. The studies were carried out before their release from military service. The investigated persons were mainly 22 years old. Aul also notes that some anthropologists did not consider it correct to study servicemen's body build, as they were persons whom the medical commission had found suitable for military service, and, therefore, they were persons with good mental and physical health [2].

In Aul's opinion, there were good conditions for anthropological measuring in the Estonian army. Aul also followed the rule that all Estonian towns, counties and parishes should be proportionally included. At anthropological measuring, Aul followed the well-known rules of R. Martin.

In 1956, Aul [5] started a broad-based anthropometric study of Estonian schoolchildren aged 7-18 years. The study finished in 1967 . The material of the study contained the data of more than 30000 children - 14862 boys and 15195 girls.

Kaarma et al. $[9,10]$ recently published two important papers concerning Estonians' anthropology - based on women's and men's height and weight data, the means of Estonian women and men aged 20-70 years, the national norms and also the classification of somatotypes of body build were presented. The second work concerns the height and weight norms and somatotypic heightweight classification of contemporary schoolchildren (10 062 boys and 11204 girls) aged $7-18$ years. 
The aim of the present study was to investigate some anthropometric parameters - height and weight, waist and hip circumference of the male student candidates of the Institute of Sport Sciences and Physiotherapy in 2017.

Another aim of our study was to investigate the relationship between the ideal weights recommended by several authors and the actual weights of our subjects and the relationship between the anthropometric indices found by the ideal weights and the indices calculated from the actual anthropometric data.

\section{MATERIAL AND METHODS}

The subjects of the present study were 72 male student candidates of the Institute of Sport Sciences and Physiotherapy in 2017.

Total body weight was measured with a Soehnle digital scale with the precision of $0.1 \mathrm{~kg}$. During the anthropometric investigation the rules of R. Martin [7] were followed. The measurements included body height and waist and hip circumferences.

Omron ${ }^{\circledR}$ BF 300 body fat monitor (Omron/Matsusaka Co Ltd., Japan) - the hand-held BIA segmental unit - was used to assess body fat percentage. Information about the subject's height, weight, age and sex was entered into the BIA data collection equipment. The resistance value was measured for each person while he comfortably gripped the handles of the BIA unit. Feet were placed shoulder width apart, and the unit was held in front of the body. The BIA unit has electrodes planted in its handles, and the electrodes measure impedance to the current as it travels between the right and the left hand. Approximately seven seconds after pressing the start button, the fat percentage and the fat mass are shown on the display. The measurements were taken twice, and the values averaged [6].

The body mass index (BMI) was calculated: $\mathrm{BMI}=$ weight $\mathrm{kg} /$ height $\mathrm{m}^{2}$.

The ponderal index (PI) is a measure of leanness of a person; it is calculated as a relationship between mass and height: $\mathrm{PI}=$ weight $\mathrm{kg} /$ height $\mathrm{m}^{3}$.

The Rohrer index (RI) was calculated: $\mathrm{RI}=1000 \times$ weight $\mathrm{g} /$ height $\mathrm{cm}^{3}$.

The body surface area (BSA) was calculated by the formula of DuBois and DuBois: $\mathrm{BSA}=0.20247 \times$ height $\mathrm{m}^{0.725} \times$ weight $\mathrm{kg}^{0.425}$.

The body surface area was also calculated by the formula of Mosteller:

$$
\mathrm{BSA}=\sqrt{\frac{\text { weight } \mathrm{kg} \times \text { height cm }}{3600}}
$$


The waist/hip ratio was calculated: waist $\mathrm{cm} / \mathrm{hip} \mathrm{cm}$.

The waist/hip ratio percentage was calculated: waist $\mathrm{cm} /$ hip $\mathrm{cm} \times 100$.

The waist/height ratio percentage was calculated: waist $\mathrm{cm} /$ height $\mathrm{cm} \times 100$. The hip/height ratio percentage is calculated: hip $\mathrm{cm} /$ height $\mathrm{cm} \times 100$.

The radius $(\mathrm{r})$ of the waist $(\mathrm{cm})$ was calculated by formula $\mathrm{r}=\mathrm{C} / 2 \pi$.

The surface area of the waist (SAW) in $\mathrm{cm}^{2}$ was calculated by formula SAW $=\pi \times \mathrm{r}^{2}$.

The radius of the hip $(\mathrm{cm})$ was calculated by the formula $\mathrm{r}=\mathrm{C} / 2 \pi$.

The surface area (SAH) of the hip in $\mathrm{cm}^{2}$ was calculated by formula $\mathrm{SAH}=$ $\pi \times \mathrm{r}^{2}$.

The amount of time spent in sports was assessed by the subjects themselves.

Paul Broca, one of the founders of physical anthropology, was interested in the ideal weight of an individual as early as in the 19th century. Broca (1871) [11] proposed the formula for calculating an individual's ideal weight - ideal weight in $\mathrm{kg}=$ height in $\mathrm{cm}-100$.

Hamwi (1964) [11] suggested a new formula for calculating the ideal weight of a person. For men, the ideal weight could be calculated as follows: weight $(\mathrm{lb})=106+6 \times$ (height -60 inches).

Devine (1974) [11] updated the formula for calculating the ideal weight for men as follows: the ideal weight for a man in $\mathrm{kg}=50+2,3 \times$ (height -60 inches).

Robinson et al. (1983) [11] proposed the following formula for the calculation of the ideal male weight: the individual's ideal body weight in $\mathrm{kg}=52+$ $1.9 \times$ (height -60 inches).

In the same year, (1983), Miller et al. [11] calculated the ideal male weight using the new formula: male ideal weight in $\mathrm{kg}=56+1.41 \times$ (height -60 inches).

In 2000, Hammond [11] proposed to calculate the ideal weight of a man according to an advanced formula: the man's ideal weight in $\mathrm{kg}=48+1.1 \times$ (height $-150 \mathrm{~cm}$ ).

The most recent formula for calculating the ideal male weight was suggested by Peterson et al. (2016) [11]: ideal male weight in $\mathrm{kg}=2.1 \times \mathrm{BMI}+3.5$ $\times \mathrm{BMI} \times$ (height in metes -1.5 meters). The BMI is set to 22 .

\section{RESULTS}

The results of the study are presented in two tables. We would emphasize the observation that the ideal weight calculated by Devine's formula has very close values to the actual weight and, therefore, the calculated BMI, Rohrer's, ponderal index and body surface area do not differ significantly from the measured values. 
Table 1. The anthropometric data, indices and ratios of the male student candidates of the Institute of Sports Sciences and Physiotherapy of Tartu University in 2017

\begin{tabular}{|c|c|c|c|c|c|}
\hline No & Variable & Mean \pm SD & Small & Medium & Big \\
\hline 1. & Age (years) & $20.771 \pm 2.910$ & & & \\
\hline 2. & Height (cm) & $182.897 \pm 6.387$ & $\leq 179.6$ & 179.7-186.1 & $\geq 186.2$ \\
\hline 3. & Weight (kg) & $77.751 \pm 9.722$ & $\leq 72.8$ & $72.9-82.6$ & $\geq 82.7$ \\
\hline 4. & Body mass index (BMI) & $23.213 \pm 2.398$ & $\leq 21.9$ & $22.0-24.4$ & $\geq 24.5$ \\
\hline 5. & Ponderal index (PI) & $43.023 \pm 1.501$ & $\leq 41.4$ & $41.5-44.5$ & $\geq 44.6$ \\
\hline 6. & Rohrer index (RI) & $1.271 \pm 0.141$ & $\leq 1.1$ & $1.2-1.3$ & $\geq 1.4$ \\
\hline 7. & $\begin{array}{l}\text { Body surface area (BSA) DuBois } \\
\text { and DuBois } \mathrm{m}^{2}\end{array}$ & $1.992 \pm 0.141$ & $\leq 1.8$ & $1.9-2.1$ & $\geq 2.2$ \\
\hline 8. & BSA Mosteller $\mathrm{m}^{2}$ & $1.984 \pm 0.146$ & $\leq 1.8$ & $1.9-2.1$ & $\geq 2.2$ \\
\hline 9. & Waist circumference $(\mathrm{cm})$ & $79.907 \pm 5.319$ & $\leq 77.1$ & $77.2-82.6$ & $\geq 82.7$ \\
\hline 10. & Hip circumference $(\mathrm{cm})$ & $100,467 \pm 5.290$ & $\leq 97.7$ & $97.8-103.1$ & $\geq 103.2$ \\
\hline 11. & Waist/hip ratio & $0.795 \pm 0.029$ & $\leq 0.77$ & $0.78-0.81$ & $\geq 0.82$ \\
\hline 12. & Waist/hip ratio \% & $79.526 \pm 2.982$ & $\leq 77$ & $78-81$ & $\geq 82$ \\
\hline 13, & Waist/height ratio $\%$ & $43.719 \pm 2.995$ & $\leq 41$ & $42-45$ & $\geq 46$ \\
\hline 14. & Hip/height ratio \% & $54.953 \pm 2.687$ & $\leq 53.5$ & $53.6-56.3$ & $\geq 56.4$ \\
\hline 15. & Radius of the waist $\mathrm{cm}$ & $12.724 \pm 0.847$ & $\leq 12.2$ & $12.3-13.1$ & $\geq 13.2$ \\
\hline 16. & Surface area (SA) of the waist $\mathrm{cm}^{2}$ & $510.591 \pm 68.689$ & $\leq 475$ & $476-545$ & $\geq 546$ \\
\hline 17. & $\begin{array}{l}\text { Surface area of the waist/BSA } \\
\text { DuBois \% }\end{array}$ & $2.557 \pm 0.252$ & $\leq 2.3$ & $2.4-2.7$ & $\geq 2.8$ \\
\hline 18. & Radius of the hip cm & $15.497 \pm 0.842$ & $\leq 15.5$ & $15.6-16.4$ & $\geq 16.5$ \\
\hline 19. & Surface area of the hip $\mathrm{cm}^{2}$ & $805.824 \pm 85.450$ & $\leq 762$ & $763-848$ & $\geq 849$ \\
\hline 20. & $\begin{array}{l}\text { Ratio surface area of the hip/BSA } \\
\text { DuBois \% }\end{array}$ & $4.038 \pm 0,237$ & $\leq 3.8$ & $3.9-4.2$ & $\geq 4.3$ \\
\hline 21. & $\begin{array}{l}\text { Body fat percentage by Omron BF } \\
\text { monitor }\end{array}$ & $10.527 \pm 3.904$ & $\leq 8.5$ & $8.6-12.5$ & $\geq 12.6$ \\
\hline 21. & Body fat in kg-s & $8.496 \pm 3.986$ & $\leq 6.4$ & $6.5-10.5$ & $\geq 10.6$ \\
\hline 22. & Experience of sport in years & $10.881 \pm 3.324$ & $\leq 9.1$ & $9.2-12.5$ & $\geq 12.6$ \\
\hline 23. & $\begin{array}{l}\text { Exercising hours per week in } \\
\text { preparatory training period }\end{array}$ & $12.361 \pm 6.452$ & $\leq 9.1$ & $9.2-15.6$ & $\geq 15.7$ \\
\hline
\end{tabular}


Table 2. Comparison of real anthropometric data and indices of entrants of the Institute of Sports Sciences with those calculated using ideal weights

\begin{tabular}{|c|c|c|c|c|}
\hline Nr. & Author of the formula & Mean \pm SD & t-value & $\mathrm{p}$-value \\
\hline 1. & Broca & $82.897 \pm 6.387$ & 3.753 & $\leq 0.05$ \\
\hline 2. & Hamwi & $80.758 \pm 6.843$ & 2.146 & $\leq 0.05$ \\
\hline 3. & Devine & $77.616 \pm 5.783$ & 0.101 & $\geq 0.05$ \\
\hline 4. & Robinson & $74.812 \pm 4.778$ & 2.302 & $\leq 0.05$ \\
\hline 5. & Miller & $73.130 \pm 3.545$ & 3.789 & $\leq 0.05$ \\
\hline 6. & Hammond & $84.187 \pm 7.026$ & 4.552 & $\leq 0.05$ \\
\hline \multirow[t]{2}{*}{7.} & Peterson & $73.731 \pm 4.918$ & 3.130 & $\leq 0.05$ \\
\hline & BMI index & & & \\
\hline 8. & Broca & $24.738 \pm 0.204$ & 5.376 & $\leq 0.05$ \\
\hline 9. & Hamwi & $24.087 \pm 0.386$ & 3.053 & $\leq 0.05$ \\
\hline 10. & Devine & $23.166 \pm 0.133$ & 0.166 & $\geq 0.05$ \\
\hline 11. & Robinson & $22.346 \pm 0.130$ & 3.063 & $\leq 0.05$ \\
\hline 12. & Miller & $21.876 \pm 0.467$ & 4.643 & $\leq 0.05$ \\
\hline 13. & Hammond & $25.112 \pm 0.369$ & 6.641 & $\leq 0.05$ \\
\hline \multirow[t]{2}{*}{14.} & Peterson & $22.019 \pm 0.072$ & 4.223 & $\leq 0.05$ \\
\hline & Rohrer's index & & & \\
\hline 15. & Broca & $1.271 \pm 0.141$ & 4.839 & $\leq 0.05$ \\
\hline 16. & Hamwi & $1.318 \pm 0.026$ & 2.781 & $\leq 0.05$ \\
\hline 17. & Devine & $1.268 \pm 0.038$ & 0.174 & $\geq 0.05$ \\
\hline 18. & Robinson & $1.224 \pm 0.049$ & 0.073 & $\geq 0.05$ \\
\hline 19. & Miller & $1.198 \pm 0.068$ & 3.956 & $\leq 0.05$ \\
\hline 20. & Hammond & $1.374 \pm 0.028$ & 6.079 & $\leq 0.05$ \\
\hline \multirow[t]{2}{*}{21.} & Peterson & $1.205 \pm 0.046$ & 3.776 & $\leq 0.05$ \\
\hline & Reciprocal ponderal index & & & \\
\hline 22. & Broca & $42.026 \pm 0.384$ & 4.840 & $\leq 0.05$ \\
\hline 23. & Hamwi & $42.402 \pm 0.278$ & 2.781 & $\leq 0.05$ \\
\hline 24. & Devine & $42.955 \pm 0.429$ & 0.369 & $\geq 0.05$ \\
\hline 25. & Robinson & $43.475 \pm 0.591$ & 2.671 & $\leq 0.05$ \\
\hline 26. & Miller & $43.797 \pm 0.822$ & 3.956 & $\leq 0.05$ \\
\hline 27. & Hammond & $41.817 \pm 0.292$ & 6.079 & $\leq 0.05$ \\
\hline 28. & Peterson & $43.689 \pm 0.552$ & 3.775 & $\leq 0.05$ \\
\hline
\end{tabular}




\begin{tabular}{|c|c|c|c|c|}
\hline Nr. & Author of the formula & Mean \pm SD & t-value & $\mathrm{p}$-value \\
\hline & BSA by DuBois and DuBois & & & \\
\hline 29. & Broca & $2.050 \pm 0.119$ & 2.667 & $\leq 0.05$ \\
\hline 30. & Hamwi & $2.027 \pm 0.124$ & 1.581 & $\geq 0.05$ \\
\hline & Devine & $1.994 \pm 0.144$ & 0.094 & $\geq 0.05$ \\
\hline 32. & Robinson & $1.963 \pm 0.103$ & 1.409 & $\geq 0.05$ \\
\hline 33. & Miller & $1.944 \pm 0.089$ & 2.442 & $\leq 0.05$ \\
\hline 34. & Hammond & $2.064 \pm 0.126$ & 3.230 & $\leq 0.05$ \\
\hline \multirow[t]{2}{*}{35.} & Peterson & $1.950 \pm 0.104$ & 2.034 & $\leq 0.05$ \\
\hline & BSA by Mosteller & & & \\
\hline 36. & Broca & $2.052 \pm 0.115$ & 3.104 & $\leq 0.05$ \\
\hline 37. & Hamwi & $2.024 \pm 0,121$ & 1,789 & $\geq 0.05$ \\
\hline 38. & Devine & $1.985 \pm 0.108$ & 0.046 & $\geq 0.05$ \\
\hline 39. & Robinson & $1,949 \pm 0.096$ & 1.699 & $\geq 0.05$ \\
\hline 40. & Miller & $1.927 \pm 0.080$ & 2.905 & $\geq 0.05$ \\
\hline 41. & Hammond & $2.068 \pm 0.122$ & 3.746 & $\leq 0.05$ \\
\hline 42. & Peterson & $1.935 \pm 0.098$ & 2.364 & $\leq 0.05$ \\
\hline
\end{tabular}

\section{DISCUSSION}

We compared the anthropometric data - height and weight - of the subjects of this study with the latest normative values of the Estonian population according to Kaarma et al. [9]. An interesting observation was made here that the entrants were taller than the normative values of men aged 20-24 in Estonia $(t=2.386, p$ 0.05). The position of modern researchers is that body height of a person is an important signal of person's functioning and condition [12].

We were interested in investigating which somatotypes appear in the entrants when classifying them in the SD-height and weight classes published by Kaarma et al. [9]. In the above-mentioned article, Kaarma et al., classify Estonian subjects into nine classes. These are three proportional classes of height and weight - small, medium, large - and three subclasses of pycnomorphs and three subclasses of leptomorphs. The entrants we studied belonged to the following somatotype classes: small $8.6 \%$, medium $22.9 \%$, large $18.6 \%$, pycnomorphs in class I $7.1 \%$, in class II $1.4 \%$, in class III $8.6 \%$, subtypes leptomorphic somatotypes in class I $11.4 \%$, none in class II and $21.4 \%$ in class III. Comparison of the average body weight of the entrants with the mean values 
obtained using the ideal weights method also revealed an interesting situation. Only the mean values of the ideal weights calculated by Devine's formula did not differ statistically significantly from the mean values of the actual weights of the entrants. Similarly, the mean values calculated by Devine's formula, using ideal weight, calculated BMI, Rohrer's index, ponderal index, calculated body surface area, both by DuBois and DuBois formula and Mosteller formula, did not differ from the mean values of the same parameters of entrants. It should be mentioned that the principles for the classification of somatypes recommended by Kaarma et al. [10] were also used by Õun et al. [13] in their article published in Papers on Anthropology.

\section{REFERENCES}

1. Kaarma H. (2011). A short overview of the work of anthropologists of the Old Anatomical Theatre. Papers on Anthropology, XX, 2011, 16-18. https://doi.org/10.12697/poa.2011.20.03

2. Aul J. (1964). Anthropology of Estonians. Transactions of the University of Tartu. Vol. 158, Tartu (in Russian)

3. Aul J. (1974). Tables for Assessment of Physical Development of Estonian School Students. Tallinn: Valgus (in Estonian)

4. Aul J. (1977). Anthropology of Estonian Women. Transactions of the University of Tartu. Issue 438. Papers on Anthropology, III, Tartu, 5-103 (in Estonian).

5. Aul J. (1982). Anthropology of Estonian Schoolchildren. Tallinn: Valgus, 3-139 (In Estonian)

6. Omron BF 300 Body Fat Monitor Instruction Manual. 3-15.

7. Knussmann R. (1988). Anthropologie: Handbuch der Vergleichenden Biologie des Menschen. Vol 1: Wesen und Methoden der Anthropologie. Stuttgart: Gustav Fischer Verlag.

8. Martin R. (1928). Lehrbuch der Anthropologie. I-III. Jena: Verlag von Gustav Fischer.

9. Kaarma H., Veldre G., Saluste L., Lintsi M., Kasmel J., Tiit E-M., Stamm R., Toomsalu M., Arend A. (2017). On systematization of Estonian's body build data. Papers on Anthropology, 26, 1, 9-27. https://doi.org/10.12697/ poa.2017.26.1.01

10. Kaarma H., Veldre G., Saluste L., Lintsi M., Kasmel J., Tiit E-M., Stamm R., Toomsalu M., Salm E., Käärik E., Arend A. (2018). Height and weight norms and somatotypic height-weight classification of Estonian schoolchildren aged 7-18 years. Papers on Anthropology, 27, 1, 17-24.

https://doi.org/10.12697/poa.2018.27.1.02

11. https://www.topendsports.com/testing/weight-ideal.htm 
12. Hermanussen M., Scheffler C. (2019). Body height as a social signal. Papers on Anthropology, 28, 1, 47-60. https://doi.org/10.12697/poa.2019.28.1.04

13. Õun K., Hallimäe H., Saarnak E., Miglai S. (2019). Study on anthropometric measurements of school-aged boys in Pärnu city. Papers on Anthropology, 28, 1, 81-95. https://doi.org/10.12697/poa.2019.28.1.07

\section{Address for correspondence:}

Mart Lintsi

Centre for Physical Anthropology, Institute of Anatomy, University of Tartu At Estonian Naturalists' Society

Struve Street 2, Tartu 51004, Estonia

E-mail: antrop@ut.ee 